\title{
A NOTE ON MUES' CONJECTURE
}

\author{
INDRAJIT LAHIRI
}

(Received 14 September 2000 and in revised form 30 October 2000)

\begin{abstract}
We prove that Mues' conjecture holds for the second- and higher-order deriva-
\end{abstract} tives of a square and higher power of any transcendental meromorphic function.

2000 Mathematics Subject Classification. 30D35.

1. Introduction, definitions, and results. Let $f$ be a transcendental meromorphic function defined in the open complex plane $\mathscr{C}$. For a positive integer $l$ we denote by $N(r, \infty ; f \mid \geq l)$ the counting function of the poles of $f$ with multiplicities not less than $l$, where a pole is counted according to its multiplicity. Also for $\alpha \in \mathscr{C}$, we denote by $N(r, \alpha ; f \mid=1)$ the counting function of simple zeros of $f-\alpha$. We do not explain the standard definitions and notations of the value distribution theory as they are available in $[1,6]$.

In 1971, Mues [4] conjectured that for a positive integer $k$ the following relation might be true:

$$
\sum_{a \neq \infty} \delta\left(a ; f^{(k)}\right) \leq 1
$$

Mues [4] himself proved the following theorem.

THEOREM 1.1. If $N(r, f)-\bar{N}(r, f)=o\{N(r, f)\}$, then for $k \geq 2$

$$
\sum_{a \neq \infty} \delta\left(a ; f^{(k)}\right) \leq 1
$$

In this direction Ishizaki [3] proved the following result.

THEOREM 1.2. If for some $l(\geq 2) N(r, \infty ; f \mid \geq l)=o\{N(r, f)\}$, then for all $k \geq l$

$$
\sum_{a \neq \infty} \delta\left(a ; f^{(k)}\right) \leq 1
$$

Yang and Wang [7] also worked on Mues' conjecture and proved the following theorem.

THEOREM 1.3. There exists a positive number $K=K(f)$ such that for every positive integer $k \geq K$

$$
\sum_{a \neq \infty} \delta\left(a ; f^{(k)}\right) \leq 1
$$


We see that in Theorem 1.3 the set of exceptional integers $k$ is different for different function $f$. In this paper, we show that if $f$ is a square or a higher power of a meromorphic function, then the relation (1.1) holds for any integer $k \geq 2$. This result follows as a consequence of the following theorem because such a function has no simple zero.

THEOREM 1.4. If $N(r, \alpha ; f \mid=1)=S(r, f)$ for some $\alpha \neq \infty$, then for $k \geq 2$

$$
\sum_{a \neq \infty} \delta\left(a ; f^{(k)}\right) \leq 1
$$

2. Lemmas. In this section, we state two lemmas which will be needed in the proof of Theorem 1.4.

LEMMA 2.1 (see [2]). Let $A>1$, then there exists a set $M(A)$ of upper logarithmic density at most $\min \left\{\left(2 e^{A-1}-1\right)^{-1},(1+e(A-1) \exp (e(1-A)))\right\}$ such that for $k=1,2,3, \ldots$

$$
\limsup _{r \rightarrow \infty, r \notin M(A)} \frac{T(r, f)}{T\left(r, f^{(k)}\right)} \leq 3 e A .
$$

LEMMA 2.2 (see [5]). For any integer $k(\geq 0)$ and any positive number $\varepsilon(>0)$, we get

$$
(k-2) \bar{N}(r, f)+N(r, 0 ; f) \leq 2 \bar{N}(r, 0 ; f)+N\left(r, 0 ; f^{(k)}\right)+\varepsilon T(r, f)+S(r, f) .
$$

3. Proof of Theorem 1.4. Without loss of generality, we may choose $\alpha=0$. Let $g=f-\alpha$. Then $f^{(k)}=g^{(k)}$ and

$$
N(r, 0 ; g \mid=1)=N(r, \alpha ; f \mid=1)=S(r, f)=S(r, g) .
$$

Applying the second fundamental theorem to $f^{(k)}$, we get for any $q$ finite distinct complex numbers $a_{1}, a_{2}, \ldots, a_{q}$

$$
\begin{aligned}
& m\left(r, f^{(k)}\right)+\sum_{j=1}^{q} m\left(r, a_{j} ; f^{(k)}\right) \\
& \quad \leq 2 T\left(r, f^{(k)}\right)-N\left(r, 0 ; f^{(k+1)}\right)-2 N\left(r, f^{(k)}\right)+N\left(r, f^{(k+1)}\right)+S\left(r, f^{(k)}\right),
\end{aligned}
$$

that is,

$$
\sum_{j=1}^{q} m\left(r, a_{j} ; f^{(k)}\right) \leq T\left(r, f^{(k)}\right)+\bar{N}(r, f)-N\left(r, 0 ; f^{(k+1)}\right)+S\left(r, f^{(k)}\right) .
$$

By Lemma 2.2 and from (3.3) we get

$$
\begin{aligned}
\sum_{j=1}^{q} m\left(r, a_{j} ; f^{(k)}\right) \leq & T\left(r, f^{(k)}\right)+\bar{N}(r, f)+2 \bar{N}(r, 0 ; f)-N(r, 0 ; f) \\
& -(k-1) \bar{N}(r, f)+\varepsilon T(r, f)+S(r, f)+S\left(r, f^{(k)}\right) .
\end{aligned}
$$


Since $2 \bar{N}(r, 0 ; f)-N(r, 0 ; f) \leq N(r, 0 ; f \mid=1)=S(r, f)$ and $k \geq 2$, we get from (3.4)

$$
\sum_{j=1}^{q} m\left(r, a_{j} ; f^{(k)}\right) \leq T\left(r, f^{(k)}\right)+\varepsilon T(r, f)+S(r, f)+S\left(r, f^{(k)}\right) .
$$

Let $E$ be the exceptional set arising out of Lemma 2.2, the second fundamental theorem, and the condition $N(r, 0 ; f \mid=1)=S(r, f)$. We choose a sequence of positive numbers $\left\{r_{n}\right\}$ tending to infinity such that $r_{n} \notin E \cup M(A)$. Then from (3.5) we get, for $r=r_{n}$ in view of Lemma 2.1,

$$
\sum_{j=1}^{q} m\left(r_{n}, a_{j} ; f^{(k)}\right) \leq T\left(r_{n}, f^{(k)}\right)+3 e A \varepsilon T\left(r_{n}, f^{(k)}\right)+o\left\{T\left(r_{n}, f^{(k)}\right)\right\},
$$

which gives

$$
\sum_{j=1}^{q} \delta\left(a_{j} ; f^{(k)}\right) \leq 1+3 e A \varepsilon
$$

Since $\varepsilon(>0)$ is arbitrary and $q$ is an arbitrary positive number, we get from (3.7)

$$
\sum_{a \neq \infty} \delta\left(a ; f^{(k)}\right) \leq 1
$$

This proves the theorem.

ACKNOwledgement. The author is thankful to Prof K. S. L. N. Prasad, Karnataka Arts College, Dharwad, India, for drawing the author's attention to Mues' conjecture.

\section{REFERENCES}

[1] W. K. Hayman, Meromorphic Functions, Oxford Mathematical Monographs, Clarendon Press, Oxford, 1964. MR 29\#1337. Zbl 115.06203.

[2] W. K. Hayman and J. Miles, On the growth of a meromorphic function and its derivatives, Complex Variables Theory Appl. 12 (1989), no. 1-4, 245-260. MR 91e:30056. Zbl 643.30021.

[3] K. Ishizaki, Some remarks on results of Mues about deficiency sums of derivatives, Arch. Math. (Basel) 55 (1990), no. 4, 374-379. MR 91k:30073. Zbl 698.30029.

[4] E. Mues, Über eine Defekt- und Verzweigungsrelation für die Ableitung meromorpher Funktionen, Manuscripta Math. 5 (1971), 275-297 (German). MR 45\#3709. Zbl 225.30031.

[5] Y. F. Wang, On the deficiencies of meromorphic derivatives, Indian J. Math. 36 (1994), no. 3, 207-214. MR 96d:30036. Zbl 893.30019.

[6] L. Yang, Value Distribution Theory, Springer-Verlag, Berlin, 1993, translated and revised from the 1982 Chinese original. MR 95h:30039. Zbl 790.30018.

[7] L. Yang and Y. F. Wang, Drasin's problems and Mues' conjecture, Sci. China Ser. A 35 (1992), no. 10, 1180-1190. MR 94e:30009. Zbl 760.30011.

INDRAJIT LAHIRI: DEPARTMENT OF MATHEMATICS, UniVERSITy OF KALYANI, WeSt BENGAL 741235, INDIA

E-mail address: indrajit@ca12.vsn1.net.in 


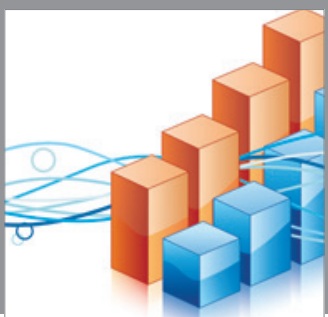

Advances in

Operations Research

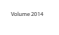

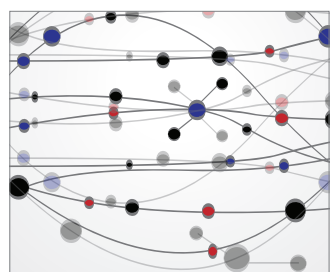

\section{The Scientific} World Journal
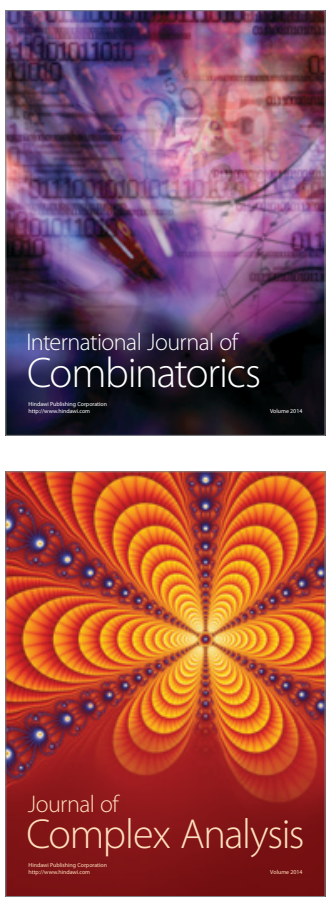

International Journal of

Mathematics and

Mathematical

Sciences
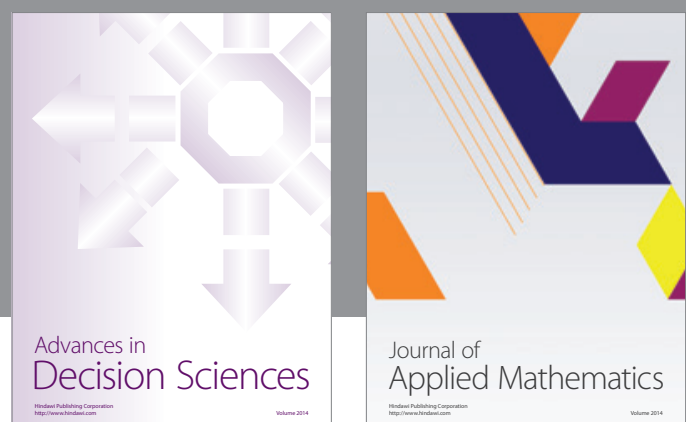

Journal of

Applied Mathematics
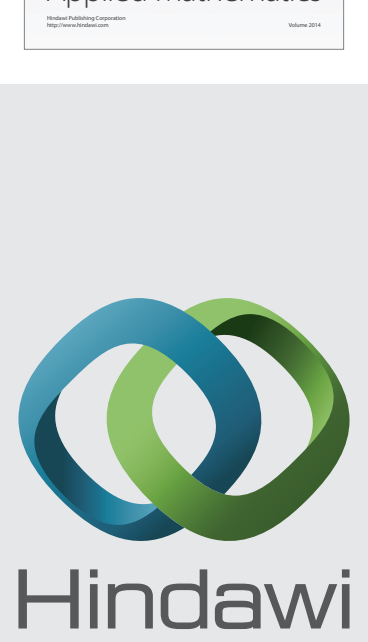

Submit your manuscripts at http://www.hindawi.com
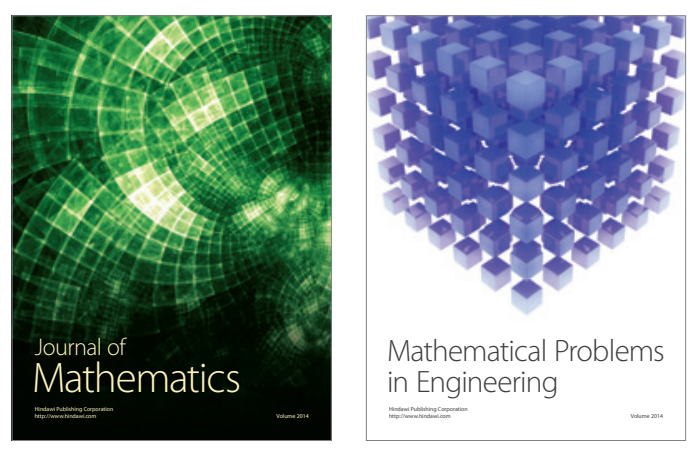

Mathematical Problems in Engineering
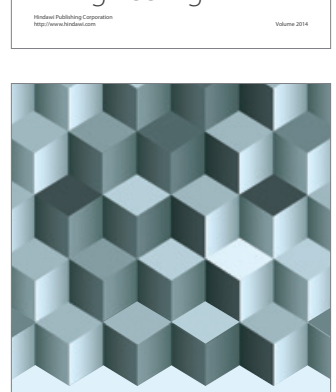

Journal of

Function Spaces
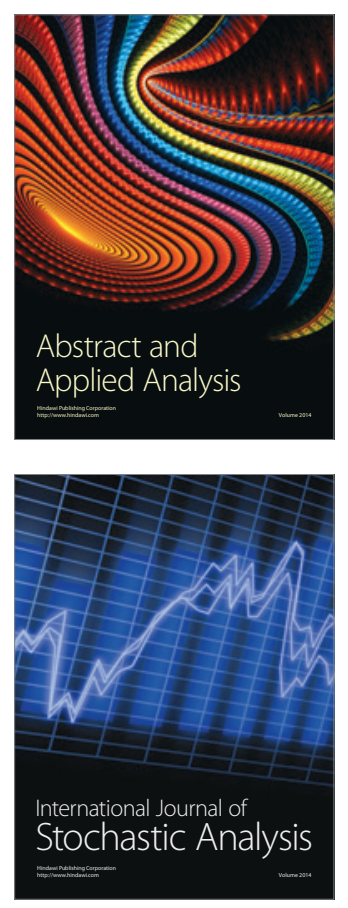

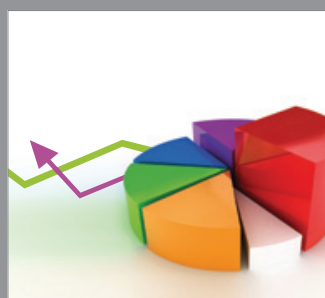

ournal of

Probability and Statistics

Promensencen
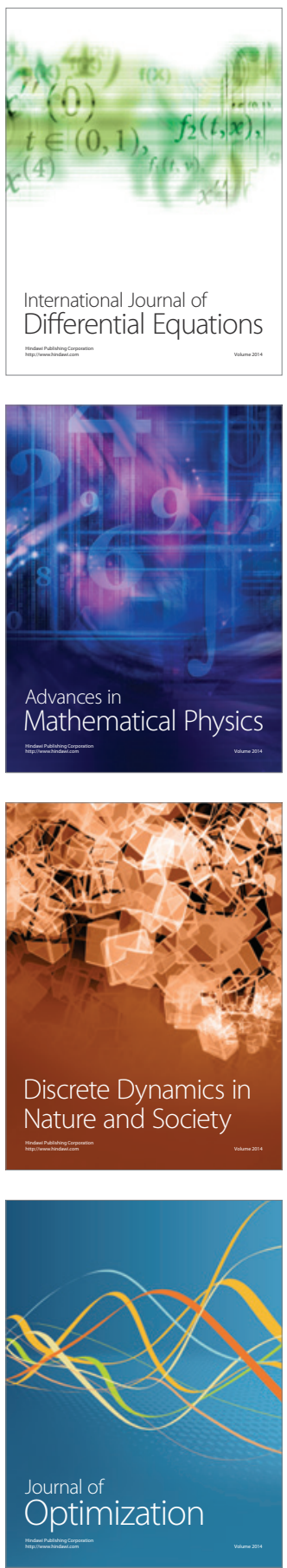